\title{
Trajectories of early secondary insults correlate to outcomes of traumatic brain injury: results from a large, single centre, observational study
}

\author{
Paola Cristina Volpi ${ }^{1{ }^{*+}}$, Chiara Robba ${ }^{2,3+}$, Matteo Rota ${ }^{4}$, Alessia Vargiolu ${ }^{5}$ and Giuseppe Citerio ${ }^{1,5}$ (B)
}

\begin{abstract}
Background: Secondary insults (SI), such as hypotension, hypoxia, and intracranial hypertension frequently occur after traumatic brain injury (TBI), and have a strong impact on patients' clinical outcomes. The aim of this study is to examine the trajectories of $\mathrm{SI}$ from the early phase of injury in the prehospital setting to hospital admission in a cohort of TBI patients.

Methods: This is a retrospective, observational, single centre study on consecutive patients admitted from 1997 to 2016 to the Neuro Intensive Care Unit (NICU) at San Gerardo Hospital, in Monza, Italy. Trajectories of SI from the prehospital to hospital settings were defined as "sustained", "resolved", "new event", and "none". Univariate and multivariate logistic regression analyses were performed to correlate SI trajectories to a 6-months outcome.

Results: Nine hundred sixty-seven patients were enrolled in the final analysis. About 20\% had hypoxic or hypotensive events and $30.7 \%$ of patients had pupillary abnormalities. Hypotension and hypoxia were associated with an unfavourable outcome when "sustained" and "resolved", while pupillary abnormalities were associated with a poor outcome when "sustained" and as "new events". After adjusting for confounding factors, 6-month mortality strongly correlated with "sustained" hypotension (OR 11.25, 95\% Cl, 3.52-35.99), "sustained" pupillary abnormalities (OR 2.8, 95\% Cl, 1.51-5.2) and "new event" pupillary abnormalities (OR 2.8, 95\% Cl, 1.16-6.76).

Conclusions: After TBI, sustained hypotension and pupillary abnormalities are important determinants for patients' outcomes. Early trajectories define the dynamics of SI and contribute to a better understanding of how early recognition and treatments in emergency settings could impact on 6-month outcomes and mortality.
\end{abstract}

Keywords: Traumatic brain injury, Secondary injuries, Prehospital insults, Trajectory, Outcome

\section{Background}

Traumatic Brain Injury (TBI) is one of the leading causes of death and disability worldwide [1]. The mortality rate is $35 \%$ and about $55-60 \%$ of survivors suffer permanent neurological impairment, with a peak in the younger population and with consequent dramatic loss of productive life-years in the affected individuals [2]. It is well known that secondary insults (SI), such

\footnotetext{
* Correspondence: paolac.volpi@gmail.com

†Paola Cristina Volpi and Chiara Robba contributed equally to this work. ${ }^{1}$ School of Medicine and Surgery, University of Milan-Bicocca, Via Cadore 48, 20900 Monza, MB, Italy

Full list of author information is available at the end of the article
}

as hypoxia, hypotension, and intracranial hypertension in the early post-traumatic phase have a negative impact on patients' outcomes [3-5]. In the International Mission for Prognosis and Analysis of Clinical Trials in Traumatic Brain Injury (IMPACT-TBI) study [3, 4], secondary insults were strongly associated with an unfavourable outcome (Odds Ratio, OR, 2.1 for hypoxia and 2.7 for hypotension), with the poorest outcome when two insults were concomitant; therefore, the Brain Trauma Foundation guidelines emphasize the importance of aggressive prevention and treatment of hypotension and hypoxia [6].

Previous studies evaluated dichotomically the presence or absence of secondary insults [7], without 
deeply exploring the effects of their evolution during the early phases of TBI, especially in the pre-hospital setting. This aspect is pivotal, since pathophysiological events are dynamic and could be potentially reversed by early treatment. Defining the trajectories of secondary insults, i.e. resolution, persistence, and new development, from the scene of the accident to hospital admission, could better describe their effects on patients' outcomes and influence the decision-making process of early treatment, both in the pre-hospital setting and in the emergency department.

The aim of this study was to examine the trajectories of secondary insults in terms of incidence and long-term effects on 6-month neurological outcomes in a large cohort of consecutive TBI patients.

\section{Materials and methods}

\section{Study design}

This is a single centre, retrospective, observational study including all consecutive TBI patients admitted to the Neuro Intensive Care Unit (NICU) at San Gerardo Hospital, Monza, Italy from January 1st, 1997 to December 31st, 2016. Ethical requirements were fulfilled, accordingly to "Decreto Legge 196", article 4 (2003). Due to the retrospective data analysis and the de-identification of sensible data, no consent was required for data utilization. Data were prospectively collected using a structured database, as previously described [8]. Patients aged $>18$ years, admitted to NICU within $24 \mathrm{~h}$ after a TBI with any Glasgow Coma Scale (GCS) [9] were considered for inclusion in the analysis. Exclusion criteria were penetrating TBI, concomitant spinal cord lesions, TBI occurred more than $24 \mathrm{~h}$ before admission, and death before admission to NICU. Patients were treated as per the Advanced Life Support (ALS) and Advanced Trauma Life Support (ATLS) guidelines in the pre-hospital settings [10].

\section{Data collection}

For each patient, we collected demographics, clinical characteristics as reported at the scene (age, sex, hour and date of trauma and hospital admission, clinical health state, pupillary reactivity and GCS, intubation and sedation), and data on the presence of extracranial lesions, including systemic bleeding, thoracic trauma, pneumothorax, abdominal trauma, limb trauma, facial trauma, pelvic fracture, spinal lesion and Computed Tomography (CT) scan at the admission, classified according to the Marshall score [11]. The assessment of clinical state before hospitalization was defined as good health, moderate or severe limitation to activity for chronic disease [12]. Data about the occurrence of secondary insults were collected at the scene, at hospital admission, and after stabilization. We considered the worst measurements recorded within the first hour at the scene and in the emergency department. Hypotension was defined as a systolic blood pressure (SBP) $\leq 90 \mathrm{mmHg}$, even in a single episode; hypoxia was defined as oxygen saturation $\left(\mathrm{SpO}_{2}\right) \leq 90 \%$, even in a single episode; and pupillary abnormalities as signs of brain herniation and dramatic intracranial pressure were defined as "normal", "bilaterally dilated, unreactive" and "anisocoric" (difference $>2 \mathrm{~mm}$ from contralateral one). Trajectories of secondary insults were defined as: "Sustained" when the insult was present in both the pre-hospital and hospital settings; "Resolved" when it was recorded in the pre-hospital setting, but not at hospital admission; "New event" when it was not documented in the pre-hospital setting, but only at the arrival at the emergency department; "None" when no insults occurred to the patient.

The primary outcome was to evaluate the incidence of trajectories of secondary insults from the pre-hospital setting to hospital admission; the secondary outcome was to correlate these trajectories to a 6-month neurological functional status. A follow-up at 6 months was conducted, by either a telephone interview or a clinical visit, using the Glasgow Outcome Scale (GOS), dichotomized into favourable (Good recovery/Moderate disability) and unfavourable outcome (Severe Disability/ Vegetative/Death) [13].

\section{Statistical analysis}

Categorical variables were reported as frequencies, continuous variable as median and range. The Chi-square test for categorical variables, or the Fisher's exact test when expected frequencies were lower than 5 , was used to compare extracranial lesions and early therapies across secondary insult trajectories. A smooth function was used to interpolate the occurrence of hypoxia, hypotension, pupillary abnormalities and age at trauma on the accident scene across year of trauma.

Univariate logistic regression was used to investigate the impact of trajectories of pupillary reactivity, hypoxia, hypotension, and their combination on 6-month outcome and mortality. Multivariate models aimed to identify the independent prognostic effect of trajectories of hypoxia, hypotension and pupillary abnormalities on 6-month unfavourable outcome and mortality were fitted after allowing for age, sex, intubation and sedation on scene, GCS, CT findings (Marshall score), presence of subarachnoid haemorrhage $(\mathrm{SAH})$ and presence of any extracranial lesions. A complete-case analysis was carried out.

The performance of multivariable logistic regression model was assessed by computing the Area Under the Receiver Operating Characteristic Curve (AUC). An AUC of 0.50 indicates that the model has no discriminative power, while a model with an AUC of 1.0 reflects perfect discrimination. 
Multivariable adjusted ORs and their 95\% Confidence Intervals (CIs) were reported in a confidence-interval plot. The magnitude of $\mathrm{SpO}_{2}$ and mean arterial pressure (MAP) was compared across SI trajectories through the nonparametric Kruskal-Wallis test, using the Dunn's test to account for multiple comparisons. Results were graphically represented through box-plots. A $p$-value $<0.05$ was considered as significant. Statistical analyses were performed using SAS 9.4 (SAS Institute, Cary, NC) and R version 3.4.0 (R Foundation, Vienna, Austria) for graphs.

\section{Results}

From 1997 to 2016, a total of 967 consecutive TBI patients admitted at the NICU of San Gerardo Hospital fulfilled the inclusion criteria and were included in the analysis (Table 1).

The mean age of the patients remarkably increased over the study period, while the prevalence of secondary injuries progressively decreased (Fig. 1a and b). About $80 \%$ of patients had no hypoxic or hypotensive events in the pre-hospital setting and at hospital admission, and $69.3 \%$ had no pupillary abnormalities (Fig. 2). Hypoxia was resolved at the admission in $19.8 \%$ of cases, was sustained in the $2 \%$, and recorded as new event in $0.4 \%$ of the patients. Hypotension was resolved at the admission in $13.6 \%$ of cases, sustained in $6.1 \%$, and observed as a new event in $2 \%$ of patients. Pupillary abnormalities were resolved at hospital admission in $6.3 \%$ of patients, sustained in $17.9 \%$, and detected as a new event in $6.5 \%$.

Oxygenation, measured as $\mathrm{SpO}_{2}$, and MAP differed between patients without SI and those with resolved SI, although the difference was not clinically relevant $\left(0.5 \%\right.$ for $\mathrm{SpO}_{2}$ and $8.7 \mathrm{mmHg}$ for MAP). No differences emerged between patients with sustained SI and those with new events; however, when patients were combined into two groups (none + resolved SI vs sustained + new events), a statistical difference was found (Fig. $3 \mathrm{a}$ and $\mathrm{b}$ ).

At the 6-month follow-up, when hypoxia and hypotension occurred and were resolved at the admission to the emergency department, the rate of poor outcomes increased $(59.3 \%$ vs $40.7 \%$ for hypoxia and $58.8 \%$ vs $41.2 \%$ for hypotension) (Fig. 4). When these secondary insults were sustained, the percentage of poor outcomes boosted up to $70.6 \%$ vs $29.4 \%$ in the hypoxia group, and to $78.8 \%$ vs $21.2 \%$ in the hypotension group. Pathological pupillary changes (sustained or new event) were associated with an unfavourable outcome (65\% vs 35 and $66.7 \%$ vs $33.3 \%$ respectively), while normal pupils (no event or resolved) at admission were associated with a good outcome.
Table 1 Characteristics of TBI population admitted to San Gerardo Hospital NICU from January 1997 - till December 2016

\begin{tabular}{|c|c|}
\hline Number TBI patients & 967 \\
\hline Median age, years & $45(0-94)$ \\
\hline \multicolumn{2}{|l|}{ Sex } \\
\hline Female & $240(25 \%)$ \\
\hline Male & $727(75 \%)$ \\
\hline \multicolumn{2}{|l|}{ Pre-TBI functional state } \\
\hline Good health & $665(69 \%)$ \\
\hline Moderate limitation of activities & $252(26 \%)$ \\
\hline Severe limitation of activities & $43(4 \%)$ \\
\hline Missing & $7(1 \%)$ \\
\hline \multicolumn{2}{|l|}{ Intubation at the scene } \\
\hline No & $435(45 \%)$ \\
\hline Yes & $532(55 \%)$ \\
\hline \multicolumn{2}{|l|}{ Sedation at the scene } \\
\hline No & $464(48 \%)$ \\
\hline Yes & $503(52 \%)$ \\
\hline \multicolumn{2}{|l|}{ GCS at the scene } \\
\hline Mild TBI [13-15] & $256(27 \%)$ \\
\hline Moderate TBI [9-12] & $157(16 \%)$ \\
\hline Severe TBI [3-8] & $554(57 \%)$ \\
\hline \multicolumn{2}{|l|}{ Intracranial lesions } \\
\hline None & $142(15 \%)$ \\
\hline Extradural haematoma & 119 (12\%) \\
\hline Subdural haematoma & $323(33 \%)$ \\
\hline Contusion & $296(31 \%)$ \\
\hline Diffusion Axonal Injury/ Petechiae & $87(9 \%)$ \\
\hline \multicolumn{2}{|l|}{ CT findings (Marshall Score) } \\
\hline Marshall 1 & $75(8 \%)$ \\
\hline Marshall 2 & $370(38 \%)$ \\
\hline Marshall 3 & $75(8 \%)$ \\
\hline Marshall 4 & $21(2 \%)$ \\
\hline Marshall 5 & $365(38 \%)$ \\
\hline Marshall 6 & $61(6 \%)$ \\
\hline \multicolumn{2}{|l|}{ Extracranial lesions } \\
\hline No & 379 (39\%) \\
\hline Yes & 588 (61\%) \\
\hline
\end{tabular}

The relationship between trajectories of secondary injuries and outcomes are described in Table 2. Sustained hypoxia and sustained hypotension were associated with poor outcomes (OR 3.26, 95\% CI 1.14-9.37, and OR 5.12, 95\% CI 2.58-10.13) and mortality (OR 6.93, 95\% CI 2.41-19.95, and OR 5.83, 95\% CI 3.2110.60). Pupillary changes were associated with poor outcome and mortality when sustained (OR 3.72, 95\% 

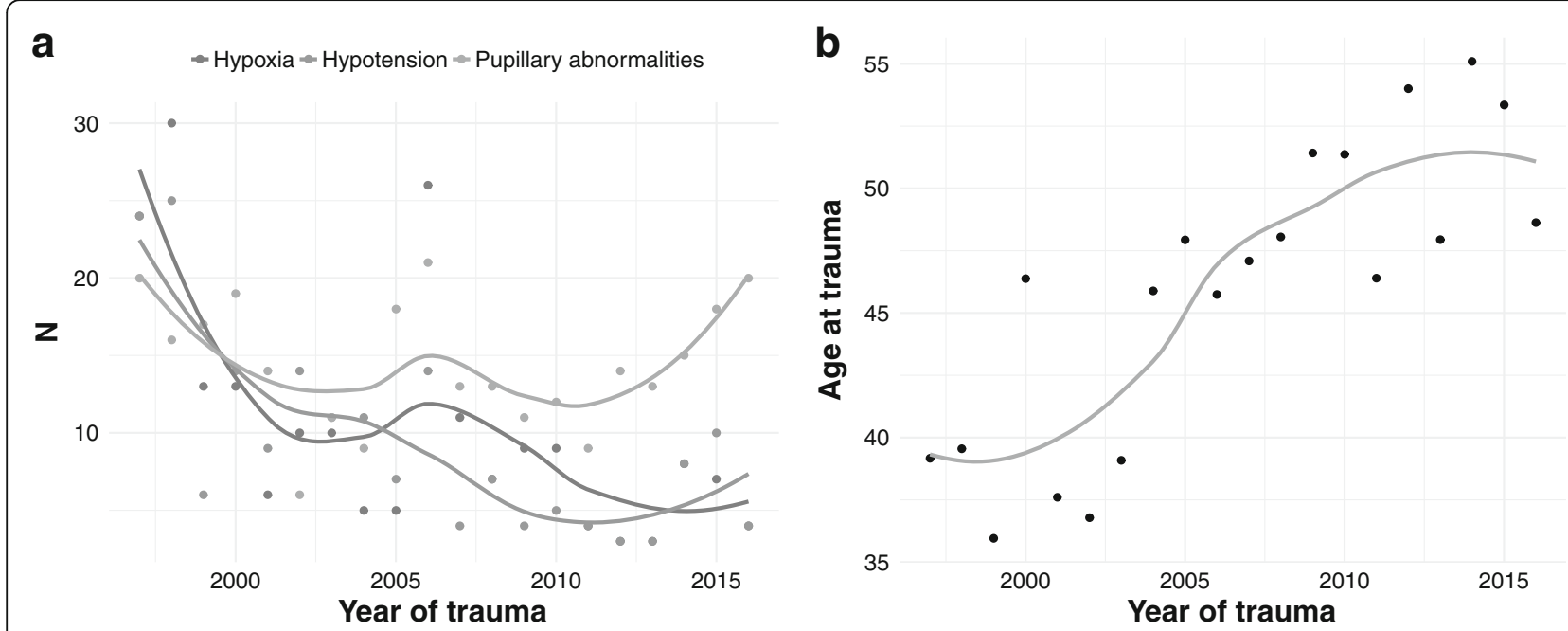

Fig. 1 Smooth function of hypoxia, hypotension and pupillary abnormalities at the scene of the accident (panel a) and age at trauma (panel b) in TBI patients admitted during the study period

CI 2.53-5.48, and OR 3.09, 95\% CI 2.07-4.63), and when it occurred as a new event (OR 4.0, 95\% CI 2.14-7.48, and OR 4.07, 95\% CI 2.21-7.49).

In the multivariate logistic regression analysis, considering as covariates age, sex, intubation and sedation on scene, GCS, CT findings (Marshall score), presence of $\mathrm{SAH}$ and presence of any extracranial lesions, trajectories of hypotension were the strongest parameter associated with mortality (OR 11.25, 95\% CI, 3.52-35.99) and unfavourable outcome (OR 3.53, 95\% CI, 1.25-9.98), especially when sustained (Fig. 5). Trajectories of pupillary changes were the best neurological indicator for outcome and mortality with minimal data dispersion. AUCs were 0.84 for unfavourable outcome at 6 months and 0.89 for mortality, indicating a high discriminatory power of the model.

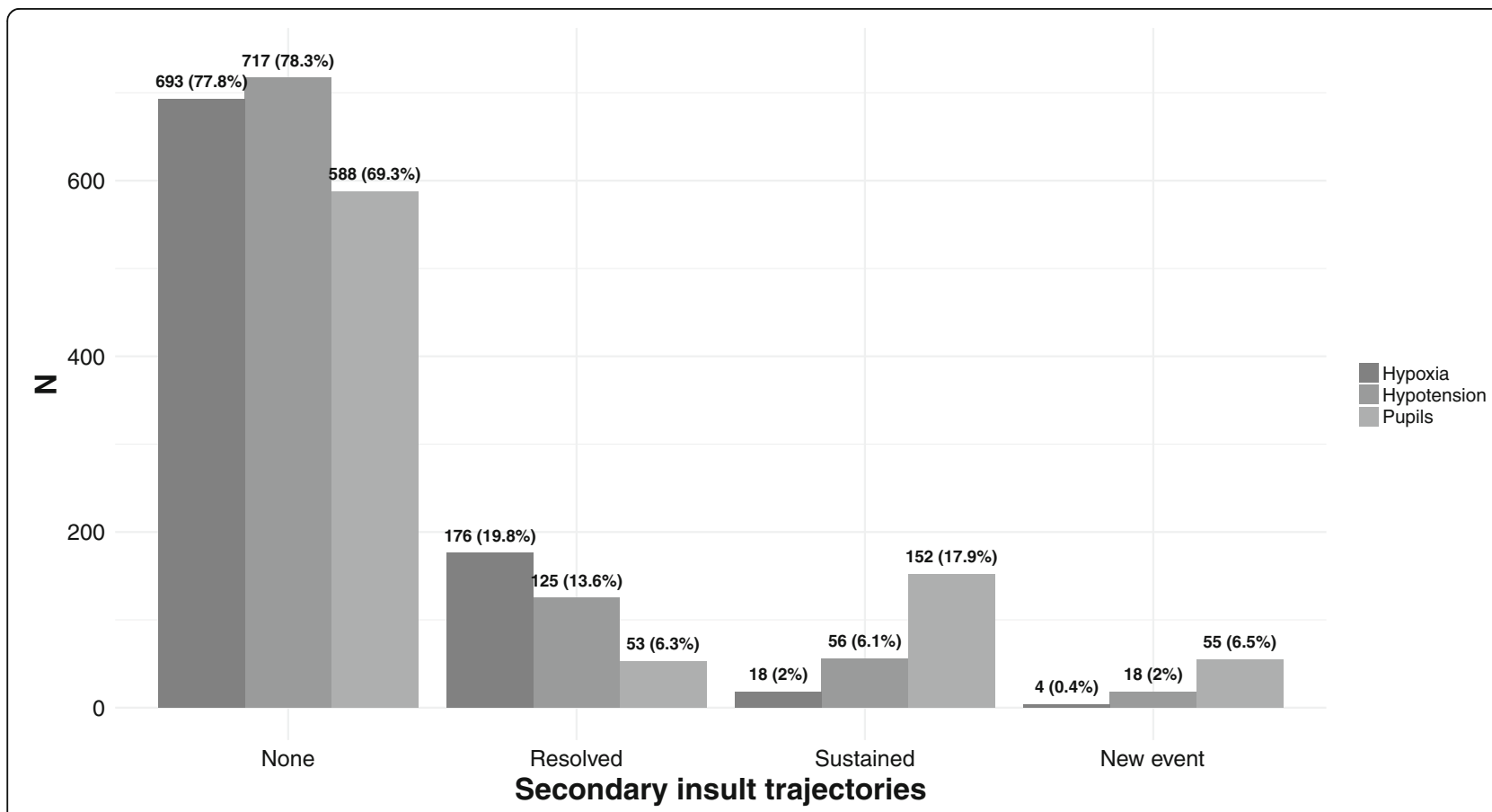

Fig. 2 Distribution of trajectories of hypoxia, hypotension, and pupillary reactivity in TBI patients admitted to San Gerardo Hospital NICU during the study period 

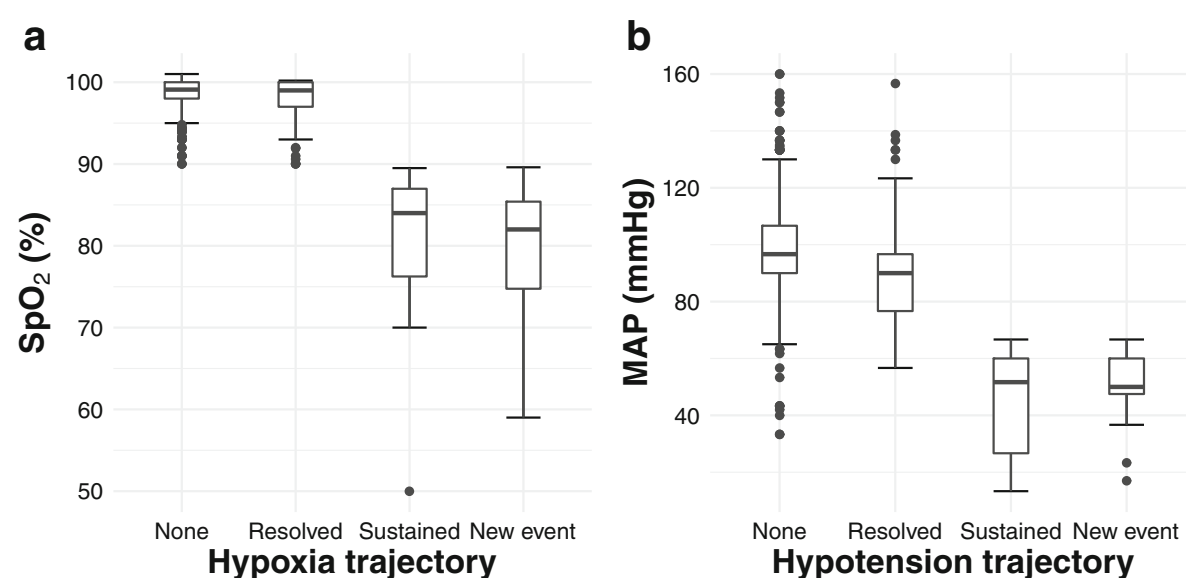

Fig. 3 Differences in oxygenation $\left(\mathrm{SpO}_{2}\right.$, Box Plot $\left.\mathbf{a}\right)$ and mean arterial pressure (MAP, Box Plot $\mathbf{b}$ ) across trajectories of hypoxia and hypotension. Box shows the interquartile range and the inner horizontal bold line indicates the median. Whiskers extend the median by \pm 1.5 times the interquartile range, while dotted points extending beyond the end of the whiskers represents outliers

We also evaluated the association between trajectories and extracranial lesions. Only 1 and 3\% of patients without extracranial injuries had persistent hypoxia and hypotension. Sixty-seven percent of patients with sustained hypoxia had the concomitant presence of chest trauma, while $61 \%$ of those with sustained hypotension presented with bleeding that required transfusions (Table 3 ). Early sedation and orotracheal intubation at the scene occurred in 64 and $82 \%$ of patients with resolved hypoxia, and among 69 and $81 \%$ of those with resolved hypotension, respectively. Interestingly, almost all patients (88\%) with sustained hypotension were intubated at scene. Pupils' trajectories had no relationship with extracranial lesions. However, a high proportion of patients with resolved (85 and 89\%) and sustained (72 and 76\%) insults were sedated and intubated at scene.

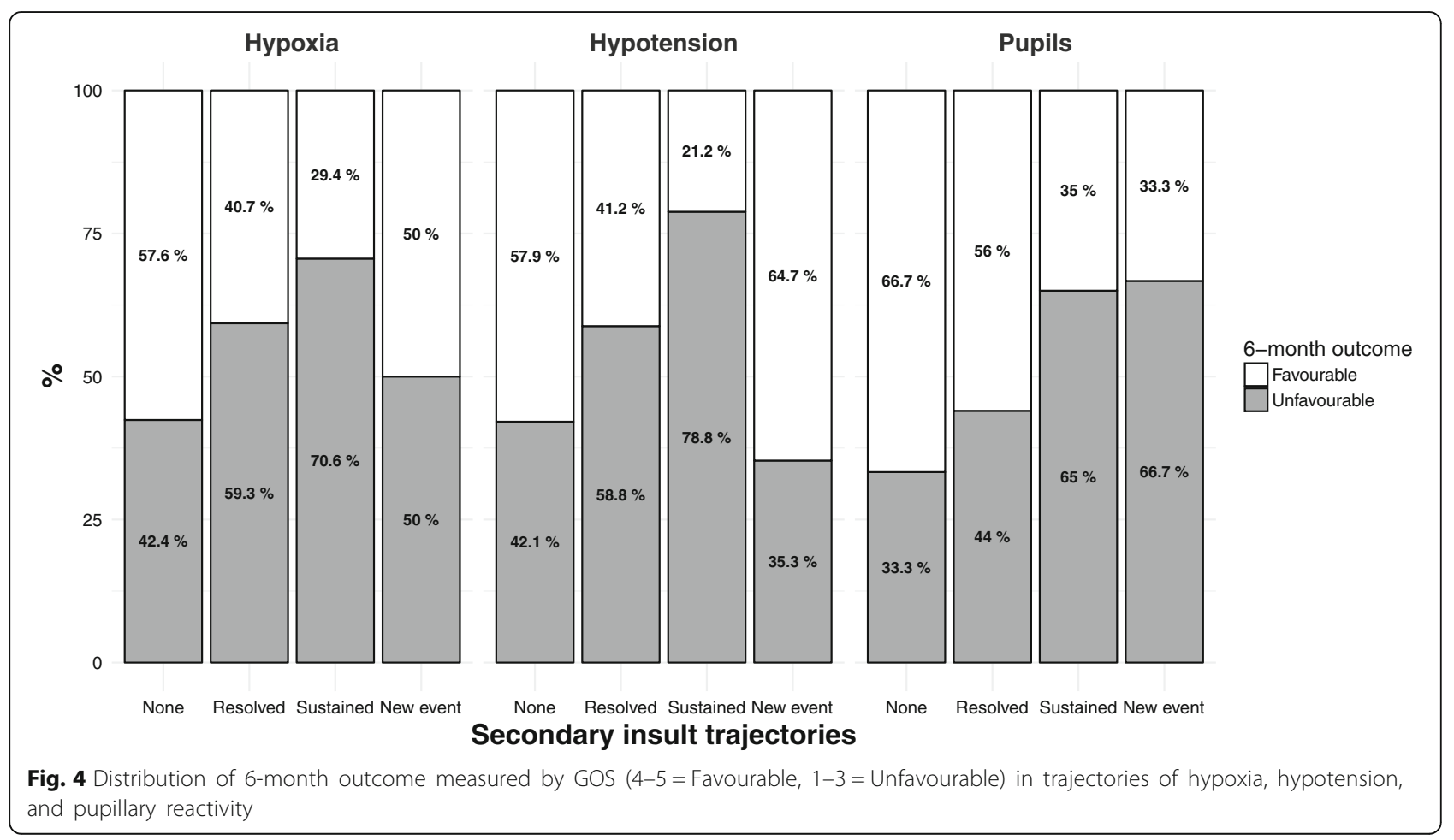


Table 2 Univariate logistic regression analyses between trajectories of hypoxia, hypotension and pupils and 6-month outcomes (measured by GOS) or 6-month mortality

\begin{tabular}{|c|c|c|c|c|c|c|c|c|}
\hline & \multicolumn{4}{|c|}{ 6-month outcome } & \multicolumn{4}{|c|}{ 6-month mortality } \\
\hline & Favourable & Unfavourable & OR $(95 \% \mathrm{Cl})$ & $P$-value & Survivors & Deaths & OR $(95 \% \mathrm{Cl})$ & $P$-value \\
\hline Number of TBI patients ${ }^{a}$ & 480 & 415 & - & & 637 & 258 & - & \\
\hline Hypoxia trajectory & & & & $<0.01$ & & & & $<0.01$ \\
\hline None & $374(78 \%)$ & $275(66 \%)$ & 1 (Reference) & & $482(76 \%)$ & $167(65 \%)$ & 1 (Reference) & \\
\hline Resolved & $61(12 \%)$ & 89 (21\%) & $1.98(1.38-2.85)$ & & $91(14 \%)$ & $59(23 \%)$ & $1.87(1.29-2.71)$ & \\
\hline Sustained & $5(1 \%)$ & $12(3 \%)$ & $3.26(1.14-9.37)$ & & $5(1 \%)$ & $12(4 \%)$ & $6.93(2.41-19.95)$ & \\
\hline New event & $2(1 \%)$ & $2(1 \%)$ & $1.36(0.19-9.72)$ & & $4(1 \%)$ & - & Not estimable & \\
\hline Missing & $38(8 \%)$ & $37(9 \%)$ & - & & $55(8 \%)$ & $20(8 \%)$ & & \\
\hline Hypotension trajectory & & & & $<0.01$ & & & & $<0.01$ \\
\hline None & $383(80 \%)$ & $279(67 \%)$ & 1 (Reference) & & $500(78 \%)$ & $162(63 \%)$ & 1 (Reference) & \\
\hline Resolved & 47 (10\%) & $67(16 \%)$ & $1.96(1.31-2.93)$ & & $67(11 \%)$ & $47(18 \%)$ & $2.17(1.43-3.27)$ & \\
\hline Sustained & $11(2 \%)$ & $41(10 \%)$ & $5.12(2.58-10.13)$ & & $18(3 \%)$ & $34(13 \%)$ & $5.83(3.21-10.60)$ & \\
\hline New event & $11(2 \%)$ & $6(2 \%)$ & $0.75(0.27-20.5)$ & & $15(2 \%)$ & $2(1 \%)$ & $0.41(0.09-1.82)$ & \\
\hline Missing & $28(6 \%)$ & $22(5 \%)$ & - & & $37(6 \%)$ & $13(5 \%)$ & & \\
\hline Pupils trajectory & & & & $<0.01$ & & & & $<0.01$ \\
\hline None & 360 (75\%) & $180(43 \%)$ & 1 (Reference) & & 447 (70\%) & 93 (36\%) & 1 (Reference) & \\
\hline Resolved & $28(6 \%)$ & $22(5 \%)$ & $1.57(0.87-2.82)$ & & $40(6 \%)$ & $10(4 \%)$ & $1.20(0.58-2.49)$ & \\
\hline Sustained & $50(11 \%)$ & $93(23 \%)$ & $3.72(2.53-5.48)$ & & 87 (14\%) & $56(22 \%)$ & $3.09(2.07-4.63)$ & \\
\hline New event & $16(3 \%)$ & $32(8 \%)$ & $4.00(2.14-7.48)$ & & $26(4 \%)$ & $22(8 \%)$ & $4.07(2.21-7.49)$ & \\
\hline Missing & $26(5 \%)$ & 88 (21\%) & - & & $37(6 \%)$ & 77 (30\%) & & \\
\hline
\end{tabular}

aSix-months outcome was not available in $72(7 \%)$ subjects

\section{Discussion}

In this study, we describe the trajectories of secondary insults in patients with TBI and their effects on 6-month clinical outcomes. Over the last decades, the epidemiology and characteristics of TBI patients have been changing [14-18]: the TBI population is becoming older [19-21], the main mechanisms of trauma are more frequently accidental falls rather than road traffic accidents; the prevalence of secondary injuries is progressively decreasing. From 1997 to 2016, the TBI patients admitted in our institution showed a progressively lower rate of hypoxia and hypotension that dropped by $7 \%$ every year, likely due to different traumatic dynamics, increased age, and the prompt treatment of secondary insults.

By defining how secondary insults evolve from the pre-hospital setting to hospital admission-namely the early trajectories- we highlighted that the dynamics of secondary injuries could be an important parameter to provide insight into the therapeutic efficacy of first-aid procedures at the scene and in the emergency department and to improve clinical outcomes of patients after TBI.

Despite the fact that the harmful effect of secondary injuries on TBI patients' outcomes has been previously described [22], little is known about the consequences of early trajectories on patients' outcome and mortality.

Our results confirm that sustained hypotension is strongly associated with unfavourable outcome and mortality. Hypotension can be difficult to control in the pre-hospital setting, especially if related to active bleeding and its occurrence is associated with a higher number of sustained events and poor outcomes [23]. Hypoxia could be potentially more easily recognized and managed even at the scene of the accident through ventilation and orotracheal intubation, thus explaining why the rate of sustained hypoxia in our population was low $(2 \%)$.

Both hypoxia and hypotension can affect cerebral perfusion pressure, resulting in brain-tissue ischaemia, further cytotoxic oedema and poor outcome [24]. In our cohort, we found few new events for both hypoxia and hypotension, likely because secondary injuries were detected early and effectively treated in the pre-hospital setting. The persistence of hypoxia and hypotension was due to concomitant extracranial injuries in polytrauma patients. Systemic bleeding, which determines systemic hypotension, was associated with poor outcome and increased mortality. Similarly, sustained hypoxia was associated with concomitant chest trauma and difficult oxygenation. However, a resolved 
a

\section{6-month unfavourable outcome}

OR $(95 \% \mathrm{Cl})$

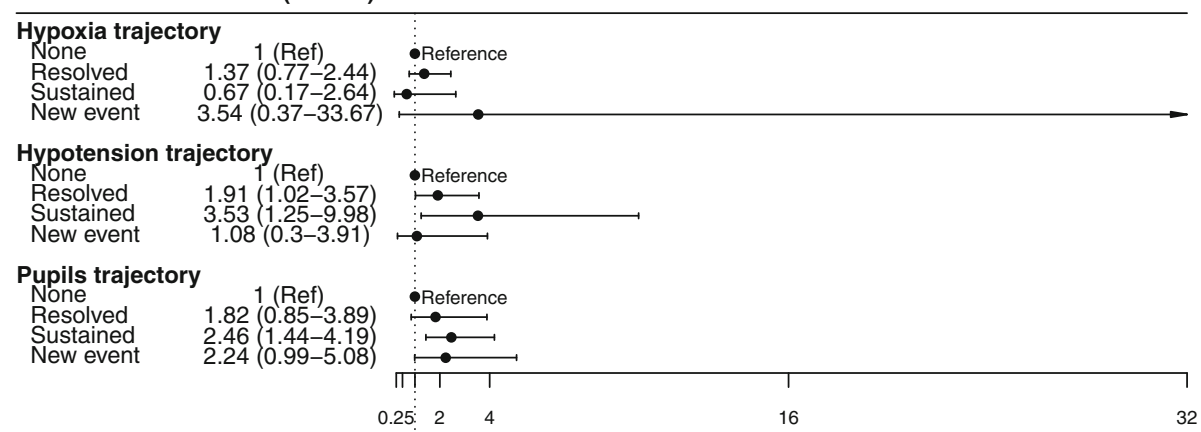

b

\section{6-month mortality}

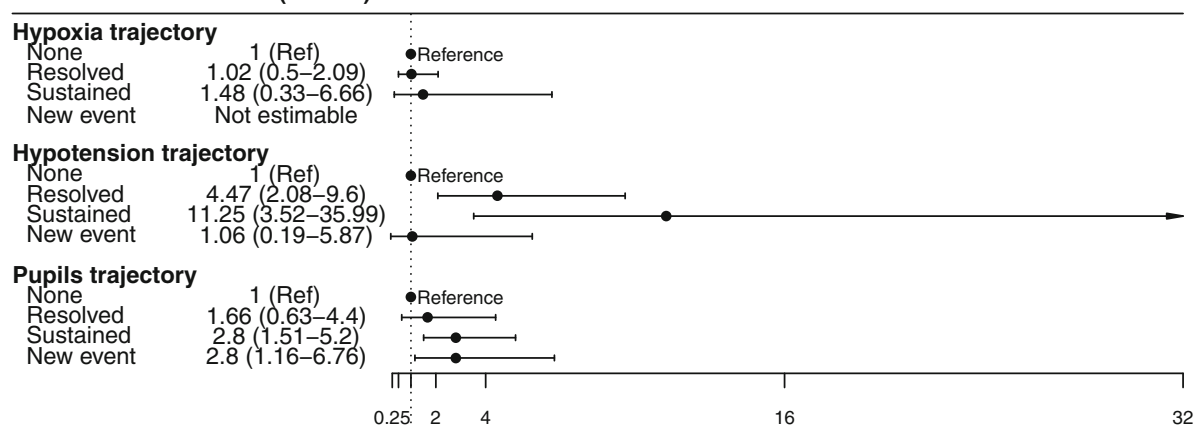

Fig. 5 Confidence interval plot of trajectories of hypoxia, hypotension, and pupils in relation to 6-month functional state (a) and 6-month mortality (b). Horizontal lines represent the 95\% conficence interval (CI). Odds Ratios (ORs) and 95\% Cls were derived from multivariate logistic regression models, adjusted for age, sex, intubation on the scene, sedation on the scene, GCS at the ED, CT classification, presence of SAH, and extracranial lesions

hypoxia at the scene [25-28] was associated with better outcomes compared to a resolved hypotension.

Pupillary changes presented a different pattern: not only the sustained event, but even the occurrence of pupillary changes as new events were strongly associated with a poor outcome. This is probably explained because dilated or unreactive pupils are late signs of high intracranial pressure that currently cannot be detected with established monitoring tools and targeted therapies in the pre-hospital settings. No association between the trajectory of pupillary changes and extracranial lesions was found. Although profound hypotension and respiratory derangement with consequent hypercapnia can determinate cerebral swelling, pupillary changes are strictly linked with the severity of TBI itself, and probably early haemodynamic management and airway control is not always sufficient to treat the neurological injury.

Therefore, our results suggest that the reversibility of a systemic insult that occurred in the early post-TBI phase is associated with an improvement of patients' outcomes. We believe that a prompt recognition of these insults and their aggressive treatment in the pre-hospital setting is mandatory, although it has not been formally proven yet to be effective $[29,30]$.

Several limitations in our study need to be mentioned. First, this is a retrospective and single centre study, reflecting our own out-of-hospital management. Therefore, with caution, generalization of the results to all TBI cases could be done. Second, there are some missing data in the database and in the clinical records, including information about the mechanism of trauma. Third, we did not analyse the details of the clinical management in the pre-hospital and hospital setting and how each intervention (ventilator parameters -inspired fraction of oxygen, positive end expiratory pressure, tidal volume-, use and type of fluids or vasopressors, osmotic therapies) modified the insults. However, as described in the methods section, treatment at the scene closely followed ALS and ATLS protocols and it should be noted that, in the emergency setting, despite existing treatment protocols, the clinician often decides on the procedures and therapies to fix deranged parameters based on the personal experience. Furthermore, the aim of our study was to understand if the resolution of an event corresponded to an improved outcome, regardless of how it was achieved. 
Table 3 Relationship between trajectories of hypoxia, hypotension, and pupils and extracranial lesions or therapies at the scene of the accident

\begin{tabular}{|c|c|c|c|c|c|c|c|c|c|c|c|}
\hline & $\begin{array}{l}\text { Extracranial } \\
\text { lesions }\end{array}$ & $\begin{array}{l}\text { Sedation } \\
\text { at scene }\end{array}$ & $\begin{array}{l}\text { Intubation } \\
\text { at scene }\end{array}$ & $\begin{array}{l}\text { Bleeding } \\
\text { requiring } \\
\text { transfusion }\end{array}$ & $\begin{array}{l}\text { Chest } \\
\text { trauma }\end{array}$ & PNX & $\begin{array}{l}\text { Abdominal } \\
\text { trauma }\end{array}$ & $\begin{array}{l}\text { Limb } \\
\text { trauma/ } \\
\text { fractures }\end{array}$ & $\begin{array}{l}\text { Facial } \\
\text { trauma/ } \\
\text { fracture }\end{array}$ & $\begin{array}{l}\text { Pelvic } \\
\text { trauma/ } \\
\text { fractures }\end{array}$ & $\begin{array}{l}\text { Amyelic } \\
\text { spinal } \\
\text { trauma }\end{array}$ \\
\hline \multicolumn{12}{|l|}{ Hypoxia trajectory } \\
\hline None $(n=693)$ & $374(54 \%)$ & $342(49 \%)$ & $335(48 \%)$ & $54(8 \%)$ & $152(22 \%)$ & $43(6 \%)$ & $57(8 \%)$ & 137 (20\%) & $188(27 \%)$ & $48(7 \%)$ & $18(3 \%)$ \\
\hline Resolved ( $n=176)$ & $136(77 \%)$ & $112(64 \%)$ & $144(82 \%)$ & 41 (23\%) & $76(43 \%)$ & $24(14 \%)$ & $27(15 \%)$ & $70(40 \%)$ & $70(40 \%)$ & $25(14 \%)$ & $11(6 \%)$ \\
\hline Sustained $(n=18)$ & $16(89 \%)$ & $6(33 \%)$ & $10(56 \%)$ & $7(39 \%)$ & $12(67 \%)$ & 7 (39\%) & $3(17 \%)$ & $3(17 \%)$ & $3(17 \%)$ & $5(28 \%)$ & $1(6 \%)$ \\
\hline New event $(n=4)$ & $3(75 \%)$ & $2(50 \%)$ & $2(50 \%)$ & $0(0 \%)$ & $1(25 \%)$ & $1(25 \%)$ & $0(0 \%)$ & $2(50 \%)$ & $2(50 \%)$ & $0(0 \%)$ & $0(0 \%)$ \\
\hline$P$-value & $<0.01$ & $<0.01$ & $<0.01$ & $<0.01$ & $<0.01$ & $<0.01$ & 0.02 & 0.11 & $<0.01$ & $<0.01$ & 0.08 \\
\hline \multicolumn{12}{|l|}{ Hypotension trajectory } \\
\hline None $(n=717)$ & $396(55 \%)$ & $355(50 \%)$ & 344 (48\%) & $49(7 \%)$ & $153(21 \%)$ & $38(5 \%)$ & $43(6 \%)$ & $136(19 \%)$ & $209(29 \%)$ & $40(6 \%)$ & $15(2 \%)$ \\
\hline Resolved ( $n=125)$ & $98(78 \%)$ & $86(69 \%)$ & $101(81 \%)$ & $26(21 \%)$ & $60(48 \%)$ & $15(12 \%)$ & $26(21 \%)$ & 41 (33\%) & $38(30 \%)$ & $25(20 \%)$ & $10(8 \%)$ \\
\hline Sustained $(n=56)$ & $50(89 \%)$ & $27(48 \%)$ & $49(88 \%)$ & $34(61 \%)$ & $29(52 \%)$ & 19 (34\%) & $15(27 \%)$ & $16(29 \%)$ & $24(43 \%)$ & $13(23 \%)$ & $5(9 \%)$ \\
\hline New event $(n=18)$ & $13(72 \%)$ & $9(50 \%)$ & $8(44 \%)$ & $1(6 \%)$ & 7 (39\%) & $1(6 \%)$ & $4(22 \%)$ & $5(28 \%)$ & $9(50 \%)$ & $4(22 \%)$ & $1(6 \%)$ \\
\hline$P$-value & $<0.01$ & $<0.01$ & $<0.01$ & $<0.01$ & $<0.01$ & $<0.01$ & $<0.01$ & 0.03 & 0.05 & $<0.01$ & $<0.01$ \\
\hline \multicolumn{12}{|l|}{ Pupils trajectory } \\
\hline None $(n=588)$ & $348(59 \%)$ & 264 (45\%) & $249(42 \%)$ & $53(9 \%)$ & $146(25 \%)$ & $44(7 \%)$ & $47(8 \%)$ & $130(22 \%)$ & $162(28 \%)$ & $48(8 \%)$ & $21(4 \%)$ \\
\hline Resolved $(n=53)$ & $32(60 \%)$ & 45 (85\%) & 47 (89\%) & $4(8 \%)$ & $20(38 \%)$ & $7(13 \%)$ & $7(13 \%)$ & $8(15 \%)$ & 17 (32\%) & $5(9 \%)$ & $2(4 \%)$ \\
\hline Sustained $(n=152)$ & $95(63 \%)$ & 109 (72\%) & $116(76 \%)$ & $21(14 \%)$ & 47 (31\%) & $12(8 \%)$ & $17(11 \%)$ & $32(21 \%)$ & $61(40 \%)$ & $14(9 \%)$ & $3(2 \%)$ \\
\hline New event $(n=55)$ & 24 (44\%) & $23(42 \%)$ & 27 (49\%) & $5(9 \%)$ & $5(9 \%)$ & $2(4 \%)$ & $1(2 \%)$ & $7(13 \%)$ & 12 (22\%) & $6(11 \%)$ & $1(2 \%)$ \\
\hline$P$-value & 0.10 & $<0.01$ & $<0.01$ & 0.32 & $<0.01$ & 0.32 & 0.08 & 0.28 & 0.1 & 0.81 & 0.81 \\
\hline
\end{tabular}

\section{Conclusion}

Early trajectories of secondary injuries can be useful to define their evolution and to better understand how early emergency treatment could impact patients' outcomes after TBI. We found that the pre-hospital treatment and resolution of systemic physiological derangement were associated with improved outcomes. Sustained hypotension was the strongest determinant of a negative outcome. Further prospective studies using standardized treatment protocols will be needed to confirm our findings.

\section{Abbreviations}

ALS: Advance Life Support; ATLS: Advanced Trauma Life Support; AUC: Area Under the Receiver Operating Characteristic Curve; Cl: Confidence Interval; CT: Computed Tomography; GCS: Glasgow Coma Scale; GOS: Glasgow Outcome Scale; IMPACT: International Mission on Prognosis and Analysis of Clinical Trials; MAP: Mean Arterial Pressure; NICU: Neuro Intensive Care Unit; OR: Odds Ratio; SAH: Subarachnoid Haemorrhage; SBP: Systolic Blood Pressure; SI: Secondary Insults; $\mathrm{SpO}_{2}$ : pulse oximeter's measure of arterial saturation; TBI: Traumatic Brain Injury

\section{Acknowledgements}

Not applicable.

\section{Funding}

No external funding has been obtained for this research.

\section{Availability of data and materials}

The datasets used and analysed during the current study are available from the corresponding author on reasonable request.

\section{Authors' contributions}

GC contributed to conception and design of the study. PCV and AV contributed to acquisition and analysis of data for the work. MR performed the statistical analysis. PCV and CR wrote the first draft of the manuscript, with input from all the co-authors. All the authors revised and approved the final version of the manuscript.

\section{Ethics approval and consent to participate}

Ethical requirements were fulfilled, accordingly to "Decreto Legge 196", article 4 (2003). Due to the retrospective data analysis and the de-identification of sensible data, no consent was required and no consent was required for data utilization. Ethical Committee and the hospital data protection office approved data utilization and publication.

\section{Consent for publication}

Not applicable.

\section{Competing interests}

The authors declare that they have no competing interests.

\section{Publisher's Note}

Springer Nature remains neutral with regard to jurisdictional claims in published maps and institutional affiliations.

\section{Author details}

${ }^{1}$ School of Medicine and Surgery, University of Milan-Bicocca, Via Cadore 48, 20900 Monza, MB, Italy. ${ }^{2}$ Neurocritical Care Unit, Addenbrooke's Hospital, Cambridge University, Box 1, Addenbrooke's Hospital, Cambridge University Hospitals Trust, Hills Road, Cambridge CB2 0QQ, UK. ${ }^{3}$ Anaesthesia and Intensive Care, Policlinico San Martino IRCCS for Oncology, Largo Rosanna Benzi, 16132 Genoa, GE, Italy. ${ }^{4}$ Department of Clinical Sciences and Community Health, University of Milan, Milan, Italy. ${ }^{5}$ Neurointensive Care Unit, San Gerardo Hospital, ASST-Monza, Via G. B. Pergolesi 33, 20835 Monza, $M B$, Italy. 
Received: 12 April 2018 Accepted: 8 November 2018

Published online: 05 December 2018

\section{References}

1. Maas AIR, Menon DK, Adelson PD, Andelic N, Bell MJ, Belli A, et al. Traumatic brain injury: integrated approaches to improve prevention, clinical care, and research. Lancet Neurol. 2017:16(12):987-1048.

2. Tramonti F, Bonfiglio L, Di Bernardo C, Ulivi C, Virgillito A, Rossi B, et al. Family functioning in severe brain injuries: correlations with caregivers' burden, perceived social support and quality of life. Psychol Health Med. 2015:20(8):933-9.

3. Maas AIR, Marmarou A, Murray GD, Teasdale SGM, Steyerberg EW. Prognosis and clinical trial Design in Traumatic Brain Injury: the IMPACT study. J Neurotrauma. 2007;24(2):232-8.

4. Majdan M, Lingsma HF, Nieboer D, Mauritz W, Rusnak M, Steyerberg EW Performance of IMPACT, CRASH and Nijmegen models in predicting six month outcome of patients with severe or moderate TBI: an external validation study. Scand J Trauma Resusc Emerg Med. 2014;22:68.

5. Spaite DW, Hu C, Bobrow BJ, Chikani V, Barnhart B, Gaither JB, et al. The effect of combined out-of-hospital hypotension and hypoxia on mortality in major traumatic brain injury. Ann Emerg Med. 2017;69(1):62-72.

6. Carney N, Totten AM, O'Reilly C, Ullman JS, Hawryluk GWJ, Bell MJ, et al. Guidelines for the Management of Severe Traumatic Brain Injury, Fourth Edition. Neurosurgery. 2017;80(1):6-15.

7. McHugh GS, Engel DC, Butcher I, Steyerberg EW, Lu J, Mushkudiani N, et al. Prognostic value of secondary insults in traumatic brain injury: results from the IMPACT study. J Neurotrauma. 2007;24(2):287-93.

8. Citerio G, Stocchetti N, Cormio M, Beretta L. Neuro-link, a computerassisted database for head injury in intensive care. Acta Neurochir. 2000; 142(7):769-76.

9. Teasdale $\mathrm{G}$, Jennett B. Assessment of coma and impaired consciousness. A practical scale. Lancet Lond Engl. 1974;2(7872):81-4.

10. Nolan J, Soar J. Adult advanced life support. Resuscitation Council (UK). 2015. https://www.resus.org.uk/resuscitation-guidelines. Accessed 12 Nov 2018.

11. Marshall LF, Marshall SB, Klauber MR, Van Berkum CM, Eisenberg H, Jane JA, et al. The diagnosis of head injury requires a classification based on computed axial tomography. J Neurotrauma. 1992;9(Suppl 1):S287-92.

12. Knaus WA, Draper EA, Wagner DP, Zimmerman JE. APACHE II: a severity of disease classification system. Crit Care Med. 1985 Oct;13(10):818-29.

13. Jennett B, Bond M. Assessment of outcome after severe brain damage. Lancet Lond Engl. 1975;1(7905):480-4.

14. Brazinova A, Rehorcikova V, Taylor MS, Buckova V, Majdan M, Psota M, et al. Epidemiology of traumatic brain injury in Europe: a living systematic review. J Neurotrauma. 2016;25.

15. Peeters W, van den Brande R, Polinder S, Brazinova A, Steyerberg EW, Lingsma HF, et al. Epidemiology of traumatic brain injury in Europe. Acta Neurochir. 2015;157(10):1683-96.

16. Roozenbeek B, Maas AIR, Menon DK. Changing patterns in the epidemiology of traumatic brain injury. Nat Rev Neurol. 2013;9(4):231-6.

17. Fletcher AE, Khalid S, Mallonee S. The epidemiology of severe traumatic brain injury among persons 65 years of age and older in Oklahoma, 19922003. Brain Inj. 2007;21(7):691-9.

18. Steudel WI, Cortbus F, Schwerdtfeger K. Epidemiology and prevention of fatal head injuries in Germany--trends and the impact of the reunification. Acta Neurochir. 2005;147(3):231-42 discussion 242

19. Depreitere B, Meyfroidt G, Roosen G, Ceuppens J, Grandas FG. Traumatic brain injury in the elderly: a significant phenomenon. Acta Neurochir Suppl. 2012;114:289-94

20. Bouras T, Stranjalis G, Korfias S, Andrianakis I, Pitaridis M, Sakas DE. Head injury mortality in a geriatric population: differentiating an "edge" age group with better potential for benefit than older poor-prognosis patients. J Neurotrauma. 2007;24(8):1355-61.

21. Susman M, SM DR, Sullivan T, Risucci D, Nealon P, Cuff S, et al. Traumatic brain injury in the elderly: increased mortality and worse functional outcome at discharge despite lower injury severity. J Trauma. 2002;53(2): 219-23 discussion 223-224.

22. Chesnut RM, Marshall LF, Klauber MR, Blunt BA, Baldwin N, Eisenberg HM, et al. The role of secondary brain injury in determining outcome from severe head injury. J Trauma. 1993 Feb;34(2):216-22.
23. Stocchetti N, Furlan A, Volta F. Hypoxemia and arterial hypotension at the accident scene in head injury. J Trauma. 1996 May:40(5):764-7.

24. Marmarou A, Anderson RL, Ward JD, Choi SC, Young HF, Eisenberg HM, et al. Impact of ICP instability and hypotension on outcome in patients with severe head trauma. Spec Suppl. 1991;75(1s):S59-66.

25. Denninghoff KR, Nuño T, Pauls Q, Yeatts SD, Silbergleit R, Palesch YY, et al. Prehospital intubation is associated with favorable outcomes and lower mortality in ProTECT III. Prehospital Emerg Care. 2017;21(5):539-44.

26. Bossers SM, Schwarte LA, Loer SA, Twisk JWR, Boer C, Schober P. Experience in prehospital endotracheal intubation significantly influences mortality of patients with severe traumatic brain injury: a systematic review and metaanalysis. PLoS One. 2015;10(10):e0141034.

27. Karamanos E, Talving P, Skiada D, Osby M, Inaba K, Lam L, et al. Is prehospital endotracheal intubation associated with improved outcomes in isolated severe head injury? A matched cohort analysis. Prehospital Disaster Med. 2014;29(1):32-6.

28. Bernard SA, Nguyen V, Cameron P, Masci K, Fitzgerald M, Cooper DJ, et al. Prehospital rapid sequence intubation improves functional outcome for patients with severe traumatic brain injury: a randomized controlled trial. Ann Surg. 2010;252(6):959-65.

29. Harmsen AMK, Giannakopoulos GF, Moerbeek PR, Jansma EP, Bonjer HJ, Bloemers FW. The influence of prehospital time on trauma patients outcome: a systematic review. Injury. 2015;46(4):602-9.

30. Badjatia N, Carney N, Crocco TJ, Fallat ME, Hennes HMA, Jagoda AS, et al. Guidelines for prehospital management of traumatic brain injury 2nd edition. Prehosp Emerg Care. 2008;12(Suppl 1):S1-52.

\section{Ready to submit your research? Choose BMC and benefit from:}

- fast, convenient online submission

- thorough peer review by experienced researchers in your field

- rapid publication on acceptance

- support for research data, including large and complex data types

- gold Open Access which fosters wider collaboration and increased citations

- maximum visibility for your research: over $100 \mathrm{M}$ website views per year

At BMC, research is always in progress.

Learn more biomedcentral.com/submissions 